\title{
GEMPA BUMI BATAVIA 1699 DAN 1780: MEMORI KOLEKTIF KEBENCANAAN
}

\section{Batavia's 1699 and 1780 Earthquake: Disaster Collective Memory}

\author{
Omar Mohtar \\ Direktorat Pelindungan Kebudayaan \\ Komplek Kemdikbud, Gedung E, Lt.11 \\ Jalan Jenderal Sudirman Senayan Jakarta 10270 \\ E-mail: omarmohtar22@gmail.com
}

\begin{abstract}
This article is written to awake the collective memory of Jakarta's earthquake. History has recorded that Jakarta, which was named as Batavia before, had been struck by earthquake several times. Greatest shake of earthquake happened in Batavia was 1699 and 1780. The 1699's earthquake caused massive damage to lots of building. The situation gotten worse due to waterways and sewer breakdown as well as bad weather condition which contributed to the death of many Netherland in Batavia. Because of this disaster, Batavia has been called 'Graf der Hollanders' or the grave of Netherland people. Natural disasters happened in Batavia in the past should always be remembered. A narration of natural disaster history, which in this paper focuses on earthquakes, can be a collective memory. This collective memory is important to raise the awareness and preparedness of people who lived in earthquake prone area. As a human, once a while we need to look back of the past and understand some disasters that had happened before. Thus, we can figure out the potential disasters that will come in the future and be more ready for them.
\end{abstract}

Keywords: Natural disasters, earthquake, Batavia, history, collective memory

\begin{abstract}
Abstrak
Tujuan penulisan artikel ini adalah untuk membangkitkan kembali memori kolektif kebencanaan gempa bumi di Jakarta. Sejarah mencatat, Jakarta yang dahulu bernama Batavia pernah beberapa kali diguncang gempa bumi. Guncangan yang paling besar yang pernah mengguncang Batavia adalah gempa bumi tahun 1699 dan 1780. Gempa bumi tahun 1699 membuat kerusakan yang cukup parah. Banyak bangunan yang mengalami kerusakan akibat gempa bumi tersebut. Kondisi ini diperparah dengan rusaknya jaringan air minum dan saluran pembuangan serta kondisi cuaca Batavia saat itu yang membuat banyak orang-orang Belanda di Batavia meninggal dunia. Banyaknya orang Belanda yang meninggal membuat Batavia saat itu mendapat julukan graf der Hollanders atau kuburan orang-orang Belanda. Bencana alam yang pernah terjadi di Batavia pada masa lalu, sangat penting untuk selalu diingat. Narasi dari sejarah bencana alam, yang dalam tulisan kali ini berfokus pada gempa bumi, dapat menjadi memori kolektif pengingat bencana. Memori kolektif ini kemudian menjadi penting sebagai salah satu cara agar masyarakat yang tinggal di daerah rawan bencana gempa bumi menjadi lebih waspada terhadap bencana yang mengintai mereka. Sebagai manusia, hendaknya sesekali melihat ke masa lalu agar dapat memahami bencana yang pernah terjadi. Dengan demikian, kita dapat mengetahui potensi bencana yang mungkin akan terjadi di masa depan dan menjadi lebih siap untuk menghadapinya.
\end{abstract}

Kata Kunci: bencana alam, gempa bumi, Batavia, sejarah, memori kolektif 


\section{PENDAHULUAN}

Waktu itu, 2 Agustus 2019 malam warga dikejutkan dengan guncangan gempa bumi yang terasa di beberapa wilayah Jakarta dan sekitarnya. Dilansir dari akun Twitter milik Badan Meteorologi, Klimatologi, dan Geofisika (BMKG), pusat gempa berada 147 barat daya Sumur, Banten dengan kedalaman $10 \mathrm{~km}$ dengan kekuatan 7.4 SR dan berpotensi tsunami. Peringatan dini tsunami segera disebarkan ke daerah-daerah di pesisir selatan dan barat Banten. Peringatan dini tsunami ini kemudian dicabut oleh BMKG sekitar dua jam setelah gempa terjadi.

Indonesia terletak di kawasan yang merupakan bagian dari Cincin Api Pasifik yang merupakan jalur gunung api aktif di dunia. Cincin Api Pasifik membentang dari benua Amerika bagian selatan, Jepang, dan Indonesia. Berada di kawasan Cincin Api Pasifik membuat Indonesia menjadi rumah dari 127 gunung api aktif dan rumah bagi 90 persen gempa bumi di dunia (Arif, 2013: 36). Banyaknya gempa bumi yang terjadi di Indonesia karena adanya tiga lempeng dunia, Eurasia, Hindia-Australia, dan Pasifik yang selalu bergerak.

Sudah banyak diketahui oleh masyarakat umum mengenai bencana-bencana besar di Indonesia yang diakibatkan dari letusan gunung api, gempa bumi, dan juga tsunami. Ada beberapa letusan gunung api di Indonesia yang menjadi perhatian dunia. Tercatat 74.000 tahun yang lalu letusan Gunung Api Purba Toba yang membuat adanya gangguan iklim dan menjadi hambatan bagi bertumbuhnya jumlah populasi manusia saat itu (Hinga, 2015: 135).

Setelah letusan Gunung Purba Toba, letusan Tambora pada 1815 dan Krakatau 1888 juga termasuk ke dalam letusan gunung berapi yang besar dalam sejarah. Letusan Tambora pada 1815 membuat tiga kerajaan yang ada di sekitarnya musnah dihantam awan panas dan membuat tahun 1816 berjalan tanpa musim panas di beberapa bagian dunia. Gelombang tsunami juga menyapu pantai Besuki, Madura, dan Maluku tiga jam setelah letusan (Geria, 2012: 30). Sementara itu, gejolak Krakatau letusannya terdengar hingga Semarang (De Java Bode, 28 Agustus 1883). Bahkan, ada juga pendapat yang menyatakan suara letusannya terdengar hingga jarak 4.000 mil, itu berarti letusannya terdengar hingga Perth di selatan, Mauritus di barat, Papua Nugini di timur, hingga pesisir selatan Tiongkok di sebelah utara (Read, 2005: 83). Letusan Krakatau menghasilkan gelombang tsunami yang kemudian menyapu pantai barat Jawa dan pantai selatan Sumatera, membuat kedua daerah tersebut menjadi hancur.

Kehancuran parah juga terjadi saat gempa bumi yang diikuti tsunami melanda Ambon dan sekitarnya pada 1674. Khusus untuk wilayah timur Indonesia, gempa bumi bumi besar kerap kali terjadi. Sebelum gempa bumi tahun 1674, sudah ada sekitar enam gempa yang mengguncang Maluku dan sekitarnya, yaitu pada tahun 1629, 1648, 1657, 1659 dua kali, dan 1672 (Latief et al, 2016:51-52). Gempa bumi 1674 menjadi perhatian karena kisah salah seorang ahli botani asal Jerman Georgius Everhardus Rumphius. Saat 
gempa bumi terjadi, Rumphius sedang berada di Ambon karena sedang mempelajari tanaman-tanaman yang ada di pulau itu. 330 tahun kemudian gempa besar yang juga diikuti gelombang tsunami melanda Aceh pada 26 Desember 2004. Masih ada contoh peristiwa lain yang bisa dituliskan, salah satunya adalah gempa bumi besar yang mengguncang Batavia dan sekitarnya pada tahun 1699 yang menyebabkan kerusakan bangunan dan menelan korban jiwa (Arsip Nasional Republik Indonesia, Marginalia dari Catatan Harian 1659-1807, 5 Januari 1699). Tulisan ini dibuat dengan menggunakan metode sejarah. Menurut Kuntowijoyo dalam Pengantar Ilmu Sejarah (2013), metode sejarah terdiri dari lima tahapan yaitu pemilihan topik, pengumpulan sumber, verifikasi (kritik sejarah, keabsahan sumber), interpretasi, dan penulisan. Topik ini dipilih karena Jakarta merupakan ibukota negara dengan penduduk yang padat dan perlunya narasi-narasi sejarah mengenai bencana.

Sumber yang digunakan dalam tulisan ini terdiri dari buku-buku yang berkaitan dengan Batavia di abad ke-17 dan 18 serta yang terkait dengan peristiwa gempa bumi Batavia 1699 dan 1780. Salah satu sumber yang digunakan adalah Die Erdbeben des indischen Archipels bis zum Jahre 1857 (1913) karangan Carl Ernst Arthur Wichmann seorang geologi kelahiran Jerman. Buku yang kerap disebut juga dengan Katalog Wichmann ini berisi tentang riwayat gempa bumi yang pernah terjadi di Indonesia pada masa lalu. Satu tulisan lain yang berguna untuk penulisan artikel ini berjudul Naturalis, Dokter, dan Ahli Ilmu Bumi: Penyelidikan Gempa dan Gunung Meletus di Hindia-Belanda pada Abad ke-19 karya sejarawan Gani Achmad Jaelani yang dimuat dalam Jurnal Sejarah Volume 2 No. 2 2019. Tulisan ini memuat beberapa sumber yang bisa digunakan oleh penulis.

\section{PEMBAHASAN}

\section{Sekilas Kondisi Batavia di Akhir Abad ke-17}

Batavia, jelang abad ke-17 merupakan wilayah yang sudah ramai oleh orang-orang dan aktivitas yang sudah dilakukan di dalamnya (Error! Reference source not found.). Ada penduduk yang tinggal di dalam dan di luar benteng. Daerah luar benteng ini disebut dengan Ommelanden. Daerah luar benteng ditempati oleh penduduk miskin dan budak sedangkan di dalam benteng ditempati oleh orang-orang yang termasuk ke dalam golongan elit (Utama, 2012: 21).

Penduduk yang tinggal di dalam benteng di abad ke-17 sudah padat. Sensus yang dilakukan pada tahun 1673 penduduk yang tinggal di dalam benteng berjumlah 27.051 jiwa. Jumlah itu meningkat menjadi 30.740 di tahun 1680. Empat tahun kemudian, jumlahnya bertambah lagi menjadi 32.243 (F. S. Gasta dalam Kanumoyoso, 2011: 55). Sementara itu, penduduk yang tinggal di luar tembok berkumpul menjadi satu sesuai dengan asal daerah masing-masing. Tiap kelompok dipimpin oleh satu orang. 
Masa itu, gula menjadi salah satu komoditas penting bagi Batavia. Perkebunan tebu banyak tersebar di wilayah Batavia dan sekitarnya. Berdirinya perkebunan dan industri gula ini tidak lepas dari peranan orang-orang Cina yang berada di Batavia, Benteng Cisadane Tangerang (Tim Kompas, 2008: 186). Namun, industri gula di Batavia ini mengalami penurunan yang sangat drastis sebagai efek dari Geger Pacinan yang terjadi pada tahun 1740.

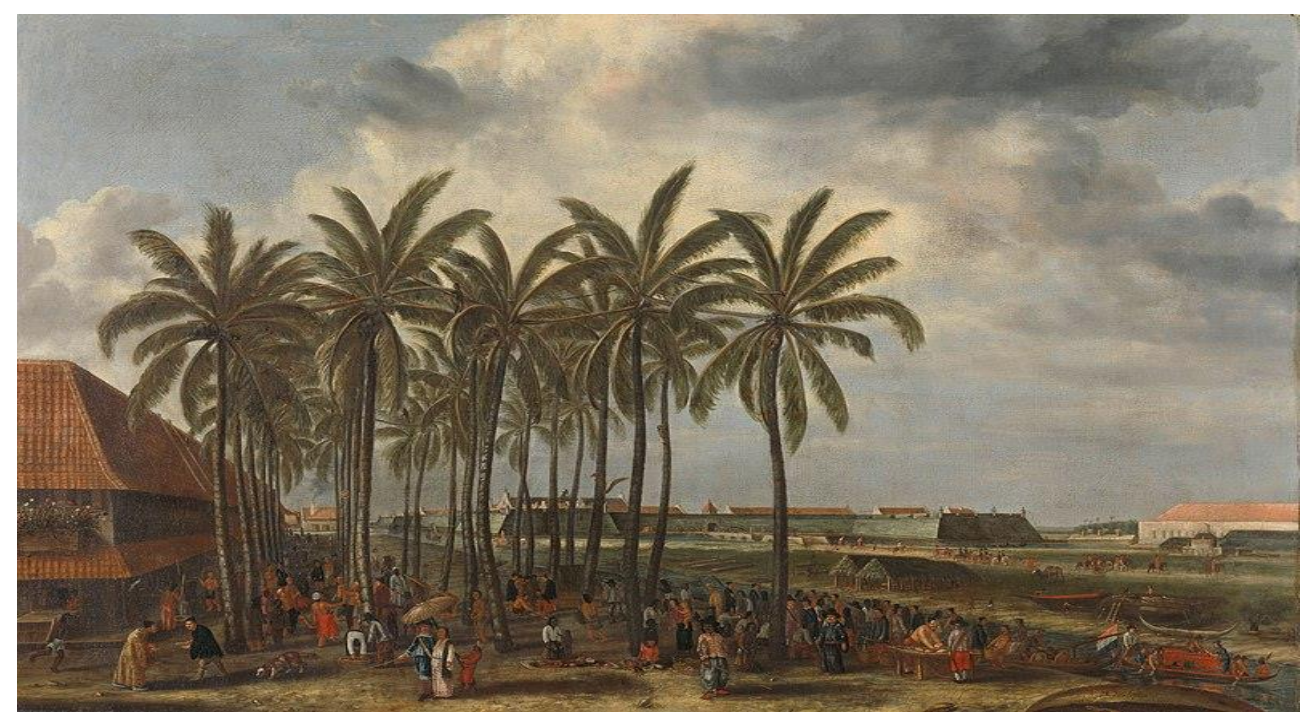

Gambar 1. Lukisan suasana Batavia tahun 1669 karya Andries Beeckman Sumber: https://www.rijksmuseum.nl/nl/collectie/SK-A-19, diakses pada Senin, 12 Oktober 2020

\section{Gempa Bumi 1699}

5 Januari dini hari hujan lebat turun mengguyur Batavia. Namun, hujan berubah menjadi kepanikan karena tiba-tiba bumi berguncang dengan hebat. Guncangan terasa pada pukul 01.30 dini hari dan berlangsung selama sekitar 15 menit (Wichmann, 1918: 49). Gempa bumi terasa tidak hanya di Batavia. Daerah lain seperti Banten dan pantai selatan Sumatera khususnya Lampung.

Guncangan gempa bumi membuat bangunan-bangunan yang ada di Batavia banyak yang retak. Menurut Arthur Wichmann, total ada 21 rumah, 20 lumbung padi, dan satu gudang yang rusak, serta 28 orang yang tewas akibat peristiwa itu. Selain membuat rumahrumah rusak, gempa bumi juga membuat penduduk Batavia saat itu takut untuk kembali ke rumah. Mereka memilih untuk tinggal sementara di tempat terbuka dan di kapal-kapal yang mereka miliki (De Locomotief, 22 Oktober 1878). Kerusakan sebagai akibat langsung dari gempa bumi 1699 tidak terlalu buruk. Akan tetapi, dampak tidak langsung dari gempa tersebut yang kemudian membuat kondisi Batavia dan penduduknya menjadi tidak baik. Gempa bumi membuat tanah longsor di sekitar lereng Gunung Salak (Nguyen et al., 2015: 16). Material longsor membawa tanah dan lumpur ke sungai yang mengalir ke Batavia, 
salah satunya Sungai Ciliwung. Material-material ini membuat sungai-sungai di Batavia menjadi tersumbat. Pasokan air bersih menjadi terganggu karena air di sungai hanya sedikit yang mengalir dan kondisinya kotor karena tercampur dengan material-material longsoran Gunung Salak.

Upaya-upaya dilakukan untuk mengatasi masalah tersumbatnya sungai. Pemerintah lalu mempekerjakan 3.400 penduduk untuk membersihkan penyumbatan di sungai agar air dapat kembali mengalir (De Locomotief, 22 Oktober 1878). Namun, upaya tersebut nyatanya tidak berjalan seperti yang diharapkan. Hal tersebut membuat kondisi kesehatan di Batavia menjadi memburuk. Sejak saat itu, banyak orang-orang di Batavia yang meninggal. Dalam tiap tahun 1.000 sampai 2.000 orang yang meninggal, dokter-dokter yang ada juga tak mampu menangani masalah ini (Lombard, 1996: 71). Kondisi kesehatan semakin buruk karena juga diperparah dengan kondisi cuaca Batavia yang saat itu sedang dilanda musim pancaroba yang membuat orang-orang terkena demam panas (Taim, 2004: 82).

Ada beberapa pendapat terkait asal gempa bumi yang terjadi pada tahun 1699 ini. Pendapat pertama, gempa bumi diakibatkan oleh letusan Gunung Salak yang berada di Buitenzorg. Beberapa tokoh yang menyatakan pendapat ini adalah Franz Wilhelm Junghuhn, J. Hageman, dan Charles Lyell. J. Hageman berdasarkan pelacakannya menyebut letusan Gunung Salak membuat gempa bumi terjadi (Hageman, 1868: 343). Ia memperkuat pendapat dari Franz Wilhelm Junghuhn yang juga menyatakan hal yang sama pada tahun 1838 dan 1845.

Pendapat dari Charles Lyell juga meyakini bahwa gempa bumi diakibatkan dari letusan Gunung Salak. Ia menyebut 503 rumah di Batavia rusak dan terdengar suara letusan serta nyala api yang berasal dari Gunung Salak (Lyell, 1856: 503). Bahkan Lyell juga menulis bukan hanya manusia saja yang menjadi korban, banyak hewan-hewan seperti ikan, kerbau, binatang buas yang mati karena terbawa arus sungai yang penuh dengan material dari Gunung Salak.

Sementara itu, ada pendapat lain yang menyatakan jika gempa bumi terjadi bukan karena letusan Gunung Salak, melainkan karena aktivitas tektonik lempeng Indo-Australia. Aktivitas tektonik membuat Batavia diguncang gempa berkekuatan $8-9$ skala richter dengan pusat gempa berada di zona subduksi lempeng Indo-Australia yang berada di sekitar Bogor dengan kedalaman sekitar 100 km (Pusat Data dan Analisa Tempo, 2019 $115)$.

\section{Gempa Bumi 1780}

Setelah gempa bumi tahun 1699, Batavia tercatat 11 kali diguncang gempa hingga tahun 1780. Kejadiannya berturut-turut tahun 1700, 1706, 1722, 1737, 17439, 1754, 1757, 1765, 1769, 1772, 1776, dan 1780 (Mardiatno et al., 2019: 56). Dari gempa-gempa tersebut, gempa tahun 1722, 1757, dan 1780 merupakan yang paling berdampak terhadap 
masyarakat Batavia. Gempa bumi yang terjadi pada tahun 1722 diikuti juga dengan naiknya gelombang air laut sedangkan gempa tahun 1757 gempa bumi berguncang cukup kuat (Wichmann, 1918: 52 dan 58).

22 Januari 1780, Batavia kembali diguncang gempa yang tidak kalah besar dengan gempa yang terjadi pada 1699. Getaran dirasakan pada pukul 14.49 (Radermacher, 1780: 51--52). Kuatnya guncangan membuat bangunan-bangunan yang ada di Batavia saat itu mengalami kerusakan (Arsip Nasional Republik Indonesia, Marginalia dari Catatan Harian 1659-1807, 22 Januari 1780). Salah satu bangunan yang rusak adalah observatorium milik pendeta yang tertarik dengan astronomi, Johan Maurits Mohr. Observatorium ini memiliki enam lantai dengan puncak atap datarnya setinggi 30,5 meter dari permukaan tanah serta memiliki panjang 22,5 meter dan lebar 17,5 meter ("Melacak Tapak Observatorium Tertua di Indonesia," 2015). Bangunan enam lantai ini saat itu merupakan bangunan tertinggi di Batavia (Error! Reference source not found.).

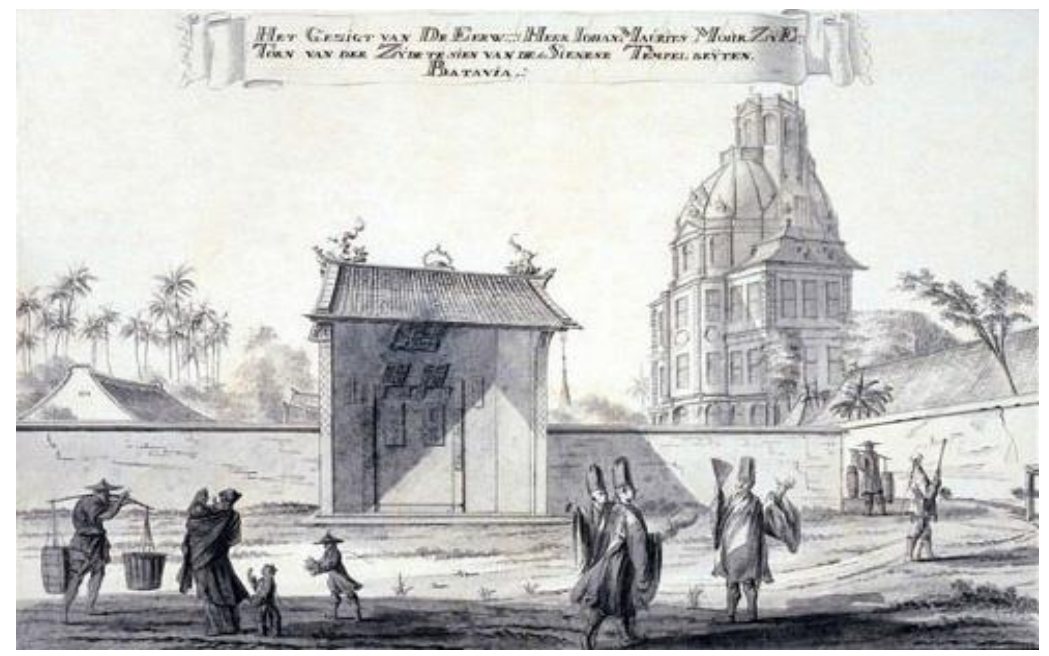

Gambar 2. Lukisan Observatorium Mohr karya Johannes Rach (1770) Sumber: https://commons.wikimedia.org/wiki/File:Observatory-of-MohrChinese-temple-1770.jpg, diakses pada Senin, 12 Oktober 2020.

Getaran gempa dirasakan hingga seluruh bagian Pulau Jawa dan bagian selatan Sumatera, merusak 27 rumah dan gudang (Wichmann, 1918: 71). Muncul berbagai dugaan sumber gempa berasa. Ada kemungkinan gempa bumi yang berkekuatan 8 SR ini berasal dari sesar Baribis (Pusat Data dan Analisa Tempo, 2019: 116). Cukup banyak laporan yang menuliskan mengenai gempa ini. Salah satunya berasal dari Kapal Willem Fredrick yang melaporkan guncangan di sekitar Selat Sunda (Mardiatno et al., 2019: 57). Gempa bumi ini juga membuat Gunung Salak dan Gunung Gede menunjukan peningkatan aktvitas vulkanik. Tidak lama setelah gempa terjadi, terdengar suara letusan dari arah Gunung Salak dan terlihat kepulan asap dari puncak Gunung Gede (Nguyen et al., 2015: 20). 


\section{Memori Kolektif Kebencanaan}

Sebagai wilayah yang kerap dilanda bencana alam, pengetahuan mengenai penyelenggaraan penanggulangan bencana menjadi penting. Masalah tersebut sudah diatur dalam Undang-undang Nomor 24 Tahun 2007 tentang Penanggulangan Bencana. Ada tiga hal yang perlu diperhatikan dalam penyelenggaraan penanggulangan bencana, yaitu, kesiapsiagaan, peringatan dini, dan mitigasi bencana.

Mitigasi bencana lalu menjadi penting bagi masyarakat yang tinggal di daerah rawan bencana. Dalam Pasal 47 UU Nomor 24 Tahun 2007 tentang Penanggulangan Bencana mitigasi bencana dilakukan untuk mengurangi resiko bencana bagi masyarakat yang berada pada kawasan rawan bencana. Dalam mitigasi bencana yang tercantum pada Pasal 47, ada tiga hal yang harus dilakukan, pelaksanaan tata ruang, pengaturan pembangunan, pembangunan infrastruktur, tata bangunan, dan penyelenggaraan pendidikan, penyuluhan, dan pelatihan baik secara konvensional maupun modern.

Memori kolektif dapat memainkan perannya pada mitigasi bencana dalam penyelenggaraan pendidikan dan penyuluhan. Banyak daerah di Indonesia yang mempunyai tinggalan memori kolektif mengenai kebencanaan, salah satu diantaranya adalah hikayat smong yang berkembang di masyarakat Simeulue. Smong merupakan kisah yang berisi tentang tsunami, tanda-tanda tsunami, dan cara menyelamatkan diri dari tsunami yang biasa diceritakan kepada anak-anak (Desfandi, 2019: 91). Adapun peristiwa tsunami yang dimaksud dalam smong adalah yang terjadi pada tahun 1907. Setelah itu, masyarakat Simeulue menjadikan smong sebagai kisah turun-temurun sehingga masyarakatnya selalu ingat. Hal tersebut membuat masyarakat Simeulue siap saat menghadapi gempa bumi dan tsunami tahun 2004.

Perlu pengetahuan yan baik terhadap bencana alam seperti gempa bumi bagi warga Jakarta. Hal pertama perlu dilakukan salah satunya adalah menginformasikan mengenai riwayat gempa bumi di Jakarta kepada penduduk Jakarta. Pemberian informasi mengenai riwayat gempa bumi diharapkan dapat memunculkan memori kolektif warga Jakarta. Memori kolektif adalah ingatan yang dihayati dan dimiliki bersama oleh suatu kelompok sosial atau bangsa mengenai suatu peristiwa sejarah di wilayah dimana kelompok sosial atau bangsa tersebut bertempat tinggal (Hasan, 2019). Generasi muda juga dapat dilibatkan untuk memunculkan memori kolektif dengan pemberian materi mengenai riwayat gempa bumi di sekolah-sekolah. Materi tersebut, bisa saja disampaikan dalam materi pelajaran sejarah atau di luar jam pelajaran sekolah. Berkembangnya internet dan sosial media juga dapat dijadikan sarana untuk membangkitkan memori kolektif warganet khususnya yang berada di Jakarta. Membangun narasi-narasi mengenai gempa bumi ini juga bisa dilakukan. Semakin banyak narasi yang dibuat, maka warga akan semakin ingat dan paham bencana 
yang mungkin sedang mengintai mereka karena gempa bumi tak dapat ditebak kapan akan terjadi.

\section{SIMPULAN}

Berada di wilayah yang kerap dilanda bencana alam seperti gempa bumi, diperlukan pengetahuan yang baik mengenai mitigasi bencana. Jakarta, acap kali identik dengan bencana berupa banjir. Akan tetapi, sejarah mencatat gempa bumi juga pernah menghancurkan wilayah yang dahulu bernama Batavia ini. Ada dua gempa besar yang pernah melanda Jakarta dalam perjalanan sejarahnya, yaitu tahun 1699 dan 1780.

Gempa bumi 1699 membuat 21 rumah, 20 lumbung padi, dan satu gudang yang rusak, serta 28 orang yang tewas. Sementara itu, gempa bumi tahun 1780 membuat beberapa bangunan rusak, termasuk observatorium milik Johan Maurits Mohr. Riwayat gempa yang pernah terjadi hendaknya dapat diingat oleh warga Jakarta. Membangkitkan memori kolektif kebencanaan warga Jakarta penting untuk dilakukan. Caranya dapat dilakukan sesuai dengan mitigasi bencana dalam Pasal 47 UU Nomor 24 Tahun 2007 tentang Penanggulangan Bencana.

\section{DAFTAR PUSTAKA}

Arif, Ahmad. (2013). Hidup Mati di Negeri Cincin Api. Jakarta: Penerbit Buku Kompas. Arsip Nasional Republik Indonesia. Marginalia dari Catatan Harian 1659-1807. Diambil dari https://sejarah-nusantara.anri.go.id/

De Java Bode. 28 Agustus 1883.

De Locomotief. 22 Oktober 1878.

Desfandi, Mirza. (2019). Kearifan Lokal Smong dalam Konteks Pendidikan (Revitalisasi Nilai Sosial-Budaya Simeulue. Banda Aceh: Syiah Kuala University Press.

Geria, I Made. (2012). Menyingkap Misteri Terkuburnya Peradaban Tambora. Yogyakarta: Gadjah Mada University Press.

Hageman, J. (1868). Over de beweerde uitbarsting van den Goenoeng Salakh in 1699. In Natuurkundig Tijdschrift Voor Nederlandsch Indie (pp. 343--355).

Hamzah Latief, Ardito M. Kodijat, Dominic Oki Ismoyo, Bustamam, Dini Adyasari, Navisa Nurbandika, Harkunti Pertiwi Rahayu. (2016). Air Turun Naik di Tiga Negeri Mengingat Tsunami di Ambon 1950. Jakarta: UNESCO.

Hasan, Hamid. (2019). Pendidikan Sejarah dalam Rangka Pengembangan Memori Kolektif dan Jatidiri Bangsa. November 14, 2020, dari http://sejarah.upi.edu/artikel/dosen/pendidikan-sejarah-dalam-rangka-pengembanganmemori-kolektif-dan-jatidiri-bangsa/

Hinga, Bethany. D. Rinard. (2015). Ring of Fire: An Encyclopedia of the Pacific Rim's Earthquakes, Tsunamis, and Volcanoes. California: ABC-CLIO.

Kanumoyoso, Bondan. (2011). Beyond the City Wall: Society and Economic Development in the Ommelanden of Batavia, 1684-1740. Leiden University.

Kuntowijoyo. (2013). Pengantar Ilmu Sejarah. Sleman: Penerbit Tiara Wacana. 
Lombard, Denys. (1996). Nusa Jawa Silang Budaya: Batas-batas Pembaratan. Jakarta: Gramedia Pustaka Utama.

Lyell, Charles. (1856). Principles of Geology. New York: D. Appleton.

Mardiatno, D., G. I Marliyani., dan S. R. L Sampurno,. (2019). Merawat Ingatan: Bencana Alam dan Kearifan Lokal di Pulau Jawa. Jakarta: Kementerian Pendidikan dan Kebudayaan.

Melacak Tapak Observatorium Tertua di Indonesia. (2015). Diambil dari https://nationalgeographic.grid.id/read/13297532/melacak-tapak-observatorium-tertuadi-indonesia?page $=$ all

Nguyen, N., J. Griffin., A. Cipta., dan P. R Cummins,. (2015). Indonesia's Historical Earthquakes: Modelled examples for improving the national hazard map. https://doi.org/10.11636/record.2015.023

Pusat Data dan Analisa Tempo. (2019). Mengukur Daya Tahan Kota Jakarta Menghadapi Gempa Besar. Jakarta: Tempo Publishing.

Radermacher, J. C. M . (1780). Bericht wegens de zwaare aardbeving, van den 22 January 1780. Dalam Verhandelingen van Het Bataviaasch Genootschap der Kunsten en Wetenschappen (pp. 51--59). Bataviaasch Genootschap der Kunsten en Wetenschappen.

Read, Robert Dick. (2005). Penjelajah Bahari: Pengaruh Peradaban Nusantara di Afrika. Bandung: Penerbit Mizan.

Taim, Eka Asih Putrina. (2004). Gedung-gedung Tua: Refleksi Adaptasi Masyarakat Belanda di Batavia. Kalpataru Majalah Arkeologi, 17, 62--84.

Tim Kompas. (2008). Ekspedisi Anjer - Panaroekan Laporan Jurnalistik Kompas. Jakarta: Penerbit Buku Kompas.

Utama, Wildan Sena. (2012). Kehidupan Sosial-Budaya Masyarakat Tionghoa di Batavia 1900an-1930an. Lembaran Sejarah, 9(1), 19-38.

Wichmann, Arthur. (1918). Die Erdbeben des indischen Archipels bis zum Jahre 1857. Amsterdam: Johannes Müller.

\section{HASIL DISKUSI}

\section{Pertanyaan}

1. Apakah Belanda pernah melakukan penelitian terhadap naskah-naskah tradisi yang terkait dengan bencana? Apakah di masa lalu (dalam konteks masa Hindia-Belanda) ada komunitas terkenal yang menuliskan berita tentang kebencanaan?

\section{Jawaban}

1. Terkait catatan sejarah kebencanaan yang merujuk pada naskah-naskah tradisi, Arthur Wichmann dalam menyusun Katalog Wichmann salah satunya menggunakan rujukan sebuah karya dari Ronggowarsito berjudul "Pusaka Raja Jawa". Seperti yang sudah dijelaskan pula oleh Pak Eko, selain melalui catatan arsip, Wichmann juga menggunakan karya tradisi sebagai referensi. Untuk komunitas terkenal yang biasa 
menulis berita tentan kebencaan salah satunya adalah Bataviaasch Genootschap van Kunsten en Wetenschappen. 